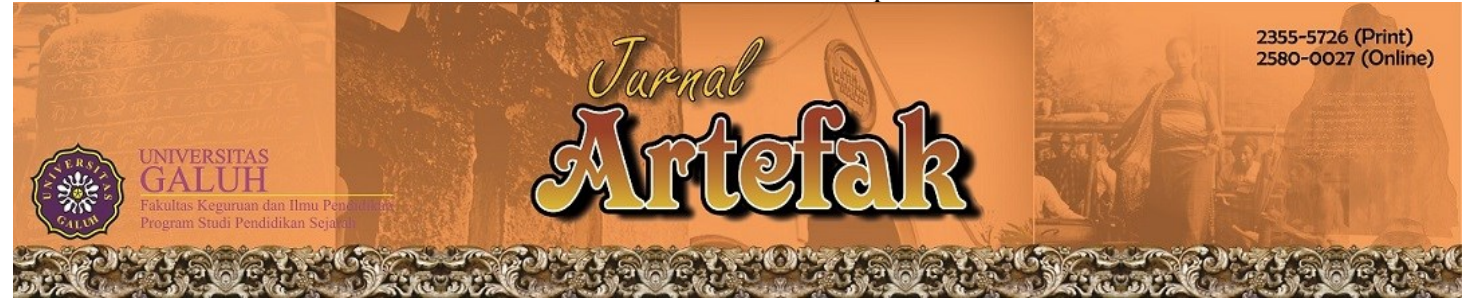

https://jurnal.unigal.ac.id/index.php/artefak/article/view/4124

\title{
IMPLEMENTASI APLIKASI MODEL PEMBELAJARAN “JELAJAH SITUS AIR MALANG RAYA" UNTUK MENUMBUHKAN KESADARAN SEJARAH LOKAL DAN UPAYA PELESTARIAN SITUS SEJARAH BAGI SISWA SMKN 2 SINGOSARI
}

\author{
Wahyu Djoko Sulistyo ${ }^{1}$, Moch. Nurfahrul L.K ${ }^{2}$, Najib Jauhari ${ }^{3}$, Maharani Arya \\ Dewanti ${ }^{4}$, Achmad Dicky Setyawan ${ }^{5}$ \\ 1,2, 3, 4, ${ }^{5}$ Universitas Negeri Malang, Indonesia, Indonesia \\ E-mail: wahyu.djoko.fis@um.ac.id ${ }^{1}$,nurfahrul.fis@um.ac.id ${ }^{2}$,najib.jauhari.fis@um.ac.id ${ }^{3}$, \\ maharaniarya12@gmail.com ${ }^{4}$, adsdicky7@gmail.com ${ }^{5}$ \\ Sejarah Artikel: Diterima 1-Maret-2021 Disetujui 15-Maret-2021 Dipublikasikan -April-2021
}

\begin{abstract}
Abstrak
Wilayah Batu, Kota Malang dan Kabupaten Malang yang dikategorikan sebagai kawasan Malang Raya menyimpan kekayaan jejak sejarah yang luar biasa. Kekayaan jejak sejarah ini sangat berpotensi untuk mendukung penghayatan dengan cara mengintegrasikan sejarah lokal pada matapelajaran sejarah. Sayangnya, sejarah lokal sebagai salah satu cabang tema dalam sejarah sering kali belum didayagunakan secara optimal pada pembelajaran sejarah, tak terkecuali di SMKN 2 Singosari. SMKN 2 Singosari merupakan sekolah kejuruan yang lokasinya tidak jauh dari beberapa situs air. Dalam pembelajaran sejarah, SMKN 2 Singosari juga memiliki problematika tidak optimalnya antusias siswa dalam pembelajaran. Berdasarkan pada data tersebut, pemanfaatan peninggalan sejarah lokal berupa situs air yang disinergikan dengan aplikasi digial JESIAMAR, menjadi upaya untuk meningkatkan ketertarikan dan penghayatan siswa terhadap sejarah yang terkemas pada agenda implementasi masyarakat. Kegiatan implementasi ini terbagi menjadi pra pelaksanaan, pelaksanaan kegiatan, dan pasca pelaksanaan. Hasil dari implementasi ini diukur dengan kuesioner yang menunjukkan jawaban yang memuaskan yaitu penilaian mengenai kesadaran sejarah lokal sebesar $85,6 \%$. Berdasarkan hasil evaluasi ini maka dapat dinyatakan bahwa aplikasi JESIAMAR sangat efektif untuk diimplementasikan dalam pembelajaran.
\end{abstract}

Kata Kunci: JESIAMAR, Situs Air, Sejarah lokal, SMKN 2 Singosari

\begin{abstract}
The Batu region, Malang City, and Malang Regency which is categorized as Malang Raya areas hold a wealth of extraordinary historical traces. The richness of historical traces has the potential to support appreciation by integrating local history into historical subjects. Unfortunately, local history as a branch of the theme in history has often not been optimally utilized in history learning, including at SMKN 2 Singosari. SMKN 2 Singosari is a vocational school which is located not far from several water sites. In history learning, SMKN 2 Singosari also has the problem of not optimal student enthusiasm in learning. Based on these data, the use of local historical relics in the form of water sites in synergy with the JESIAMAR digital application is an effort to increase students' interest and appreciation of history which is packaged in the community service agenda. This service activity is divided into pre-implementation, activity implementation, and post-implementation. The results of this service are measured by a questionnaire which shows a satisfactory answer, namely an assessment of local historical awareness of $85.6 \%$. Based on the results of this evaluation, it can be stated that the JESIAMAR application is very effective to be implemented in learning.
\end{abstract}

Keyword: JESIAMAR, Water Site, Local history, SMKN 2 Singosari 


\section{PENDAHULUAN}

Sejarah adalah bidang studi yang nuansa kepentingannya amat kental kendati dibarengi dengan tradisi keilmuan yang menuntut objektifitas dan kejujuran (Ali, 2005). Di tengah arus globalisasi budaya dan universalisasi nilai-nilai, adalah keharusan bila sejarawan menyumbangkan ilmunya kepada bangsanya dalam usaha mengenal diri sendiri agar rekayasa masa depan tetap berpijak pada jati diri bangsa (Kuntowijoyo, 2013: 113). Dalam dunia pendidikan di tingkatan SMA/MK, matapelajaran sejarah mengemban peran nyata dalam upaya mencetak generasi bangsa yang memahami jati diri bangsanya. Sayangnya, pelaksanaan pembelajaran sejarah di sekolah seringkali masih berpandangan bahwa sejarah adalah pembelajaran hafalan yang membosankan sehingga siswa cenderung menarik diri dalam pembelajaran.

Salah satu upaya untuk mendekatkan siswa dengan sejarah adalah dengan memberikan kesadaran bahwa sejarah memang ada dan dekat dengan mereka yakni dengan mengenalkan eksistensi sejarah lokal. Nyatanya, terdapat banyak sekali peninggalan sejarah lokal yang dapat dimanfaatkan sebagai sumber belajar. Menurut Prastowo sumber belajar pada dasarnya adalah segala sesuatu yang bisa menimbulkan proses belajar (Prastowo, 2014) dan sumber sejarah sangat berlimpah disekeliling kita. Pemanfaatan sumber belajar di sekitar lingkungan siswa yang terkemas dalam sejarah lokal akan meningkatkan kebanggaan dan kecintaan terhadap eksistensi sejarah disekitar mereka yang sering kali tidak terjamah materi di sekolah (W. D. Sulistyo et al., 2020; W.D Sulistyo, 2019b). Sejarah lokal dalam bentuknya yang mikro telah memiliki dasardasar dinamikanya, sehingga peristiwa sejarah dapat diterangkan melalui dinamika internal yang tiap daerah mempunyai kekhasan sendiri (Kuntowijoyo, 2013). Peristiwa sejarah lokal memiliki khasanah nilai-nilai kebaikan yang mampu dijadikan tolak ukur melangkah ke masa depan (Al Akhyar, 2020).
Permasalahan umum yang banyak dijumpai di lapangan berkaitan dengan pembelajaran sejarah bagi anak-anak sekolah menengah kejuruan adalah kondisi pembelajaran yang tidak kreatif dan inovatif. Pola-pola lama dan konvensional masih menjadi pembiasaan yang selalu dilakukan oleh guru. Pada sekolah-sekolah umum di Malang, rata-rata pembelajaran sejarah yang dilaksanakan oleh guru menggunakan pendekatan teacher centered. Temuan yang dilakukan dalam beberapa riset sebelumnya menunjukkan bahwa masih sangat jarang guru yang menggunakan media inovatif dan model pembelajaran mandiri. Terkhusus di SMKN 2 Singosari sebagai salah satu sekolah kejuruan negeri di Singosari, fenomena yang diuraikan di atas juga terjadi.

SMKN 2 Singosari merupakan sekolah yang berkomitmen jangka panjang terhadap pengembangan dan peningkatan kualitas sumber daya manusia. Banyaknya jumlah siswa yang menggantungkan masa depannya di SMKN 2 Singosari seyogyanya beriringan dengan kualitas pembelajaran yang disuguhkan pihak sekolah. Kualitas pembelajaran yang baik dan upaya-upaya mengatasi problematika dalam pembelajaran akan menunjang pencapaian hasil belajar yang optimal.

Kegiatan implementasi ini memilih SMKN 2 Singosari karena letak sekolah yang berdekatan dengan beberapa situs sejarah air seperti Petirthaan Watu Gede Kendedes dan Petirthaan Sumberawan, namun dalam kenyataanya situs sejarah air tersebut tidak pernah dimanfaatkan sebagai sumber pembelajaran. Tidak dapat dipungkiri bahwa wilayah malang memiliki potensi yang luar biasa terhadap peninggalan-peninggalan sejarah (Sayono et al., 2019). Oleh karena itu dalam kegiatan implementasi ini dirumuskan serangkaian kegiatan untuk mengimplementasikan aplikasi model pembelajaran sejarah dengan konsep menumbuhkan kemandirian siswa dalam menggali informasi sejarah di sekitarnya sebagai upaya pelestarian situs sejarah. 
Model dan media yang diterapkan di sini tersistem dalam sebuah aplikasi pembelajaran yang muatan konten isinya cukup kompleks dan menarik. Media pembelajaran merupakan "bahan, alat, maupun metode atau teknik yang digunakan dalam kegiatan belajar mengajar dengan maksud agar proses interaksi komunikatif edukatif antara guru dan siswa dapat berlangsung secara tepat guna dan berdaya guna (Latuheru, 1988; Wahyu Djoko Sulistyo et al., 2020). Media pembelajaran berupa aplikasi bernama JESIAMAR (Jejak Sejarah Malang Raya) ini merupakan produk dari pengembangan inovasi pembelajaran sejarah. Adapun kegiatan implementasinya adalah mengenalkan dan membiasakan siswa dengan pembelajaran yang inovatif dan kreatif. Selain itu, konten materi dari aplikasi pembelajaran yang mengemukakan situs air di lingkungan sekitar akan menumbuhkan kesadaran sejarah lokal bagi siswa sehingga mereka tergerak untuk turut melestarikan situs sejarah.

\section{METODE PENELITIAN}

Implementasi dari penelitian ini memfasilitasi siswa bersama guru sejarah di SMKN 2 Singosari untuk menerapkan aplikasi model pembelajaran "Jelajah Situs Air Malang Raya" atau JESIAMAR dalam pembelajaran sejarah. Adapun metode yang diterapkan adalah metode qualitative partisipan. "Partisipan merupakan aktor yang telah menjadi berpartisipasi dalam situasi aksi" (Semiawan, 2010). Dengan metode qualitative partisipan, siswa sebagai partisipan dibutuhkan secara langsung dalam kegiatan implementasi. Partisipan diajak secara langsung mengaplikasikan model pembelajaran jelajah situs air Malang Raya. Terdapat tiga tahapan dalam mengimplementasikan metode ini yaitu pra kegiatan, kegiatan inti, dan pasca kegiatan dengan rincian masing-masing tahapan sebagai berikut:

\section{Pra Kegiatan}

Pada tahap pra kegiatan, tim implementasi melakukan tinjauan lokasi kepada pihak mitra untuk melakukan analisis kebutuhan sekaligus kepengurusan kesepakatan kerjasama. Analisis yaitu menguraikan suatu permasalahan atau objek ke unsur-unsurnya dan menentukan bagaimana unsur-unsur tersebut saling berkaitan satu sama lain (Arifin, 2009). Pada tahap ini, tim implementasi melakukan pengumpulan data dengan teknik interview (wawancara) maupun observasi. Menurut Sugiyono wawancara merupakan teknik pengumpulan data apabila peneliti ingin melakukan studi pendahuluan untuk menemukan permasalahan yang harus diteliti, dan juga apabila peneliti ingin mengetahui hal-hal dari responden yang lebih mendalam (Sugiyono, 2013). Dengan demikian, sebelum pelaksanaan kegiatan implementasi, tim implementasi mampu menganalisis potensi yang mampu dikembangkan maupun kebutuhan dari pihak mitra.

2. Pelaksanaan Kegiatan

Setelah terjadi kesepakatan dan koordinasi, kegiatan implementasi dilaksanakan. Pada tahap ini, tim implementasi memastikan bahwa aplikasi yang dikembangkan telah dibagikan dan mampu dijangkau seluruh siswa selaku partisipan. Siswa dipandu untuk menginstal dan mengoperasikan aplikasi serta diberikan pengenalan mengenai beberapa situs air yang ada di lingkungan mereka. Pada tahap ini pula, siswa difasilitasi untuk melakukan kegiatan diskusi. Dengan demikian, setelah kegiatan pelaksanaan siswa dapat mengakses dan belajar secara mandiri mengenai situs air di lingkungannya menggunakan aplikasi tersebut.

3. Pasca Kagiatan

Tahap akhir dari implementasi ini adalah melakukan evaluasi dan penyusunan draf hasil implementasi. Pada tahap pasca kegiatan, tim implementasi memfasilitasi partisipan untuk mengevaluasi pelaksanaan 
kegiatan implementasi masyarakat ini dengan mengisi kuesioner penilaian pada Google Forms. Terdapat 20 siswa yang turut berpartisipasi mengisi laman evaluasi. Kegiatan evaluasi tersebut menjadi tolak ukur keberhasilan implementasi ini. Selain itu, pada tahap pasca kegiatan tim pelaksana juga melakukan revisi dan menyusun kembali laporan implementasi serta menghasilkan produk luaran.

\section{HASIL PENELITIAN DAN PEMBAHASAN}

Hasil dari implementasi aplikasi t ini dapat diuraikan dalam tiga bahasan yaitu sebagai berikut:

1. Pra Kegiatan

Pada tahap pra kegiatan, tim implementasi melakukan survei lokasi, interview dan observasi di SMKN 2 Singosari selaku pihak mitra. Tujuan dari tahapan ini adalah agar dapat bekerjasama dengan pihak mitra, menentukan waktu dan lokasi spesifik penelitian, mendapatkan daftar nama siswa sebagai partisipan, serta untuk mengetahui berbagai perlengkapan dan materi yang akan dibutuhkan pada tahap selanjutnya. Dalam hal ini, Fidda Zurika Islamiya, S.Pd selaku guru sejarah SMKN 2 Singosari turut memberikan informasi mengenai kondisi pembelajaran, potensi dan kebutuhan sekolah mitra. Pada tahap pra kegiatan ini, koordinasi tim diketuai Wahyu Djoko Sulistyo, S.Pd., M.Pd dan pihak mitra diwakili oleh Drs. H. Ahmad Maksum, M.Pd. selaku Kepala Sekolah. Setelah kesepakatan antara tim implementasi dan pihak SMKN 2 Singosari, tim implementasi melakukan koordinasi lanjutan hingga pelaksanaan kegiatan sesuai kesepakatan.

\section{Pelaksanaan Kegiatan}

Setelah terjadi kesepakatan dan koordinasi, kegiatan implementasi aplikasi model pembelajaran "Jelajah Situs Air Malang Raya" (JESIAMAR) untuk menumbuhkan kesadaran sejarah lokal dan upaya pelestarian situs sejarah bagi siswa SMKN 2 Singosari dilaksanakan. Kegiatan ini dilaksanakan secara online pada hari senin, 31 Agustus 2020 dengan memanfaatkan Google Meet. Siswa yang terlibat dalam kegiatan implementasi adalah siswa kelas X MM 3 dan X EI 2 . Susunan acara pada pelaksanaan kegiatan implementasi ini yaitu: (1) registrasi; (2) sambutan Wahyu Djoko Sulistyo, S.Pd., selaku Dosen Jurusan Sejarah; (3) penyampaian materi dari pemateri pertama yaitu Dicky Setiawan; (4) penyampaian materi dari pemateri kedua yaitu Aghnia Maghfiroh; (5) kegiatan tanya jawab; (6) doa dan penutup. Jalannya pelaksanaan kegiatan implementasi dipandu oleh Hanna Amirah selaku moderator. Pada tahap ini, pemateri pertama menyuguhkan ulasan mengenai sejarah beberapa situs air yang dekat dengan lingkungan siswa, memunculkan kesadaran bahwa sejarah ada di sekitar mereka. Ulasan materi mengenai sejarah situs air ini dilengkapi dengan sosialisasi pengoperasian aplikasi JESIAMAR oleh pemateri kedua. Siswa yang sebelumnya telah dibagikan aplikasi JESIAMAR dipandu untuk menginstal maupun mengoperasikan aplikasi tersebut. Siswa juga dikenalkan dengan berbagai fitur maupun keuntungan memanfaatkan aplikasi JESIAMAR dalam pembelajaran sejarah. Selanjutnya, siswa difasilitasi untuk kegiatan diskusi seputar materi sejarah lokal maupun aplikasi JESIAMAR. 

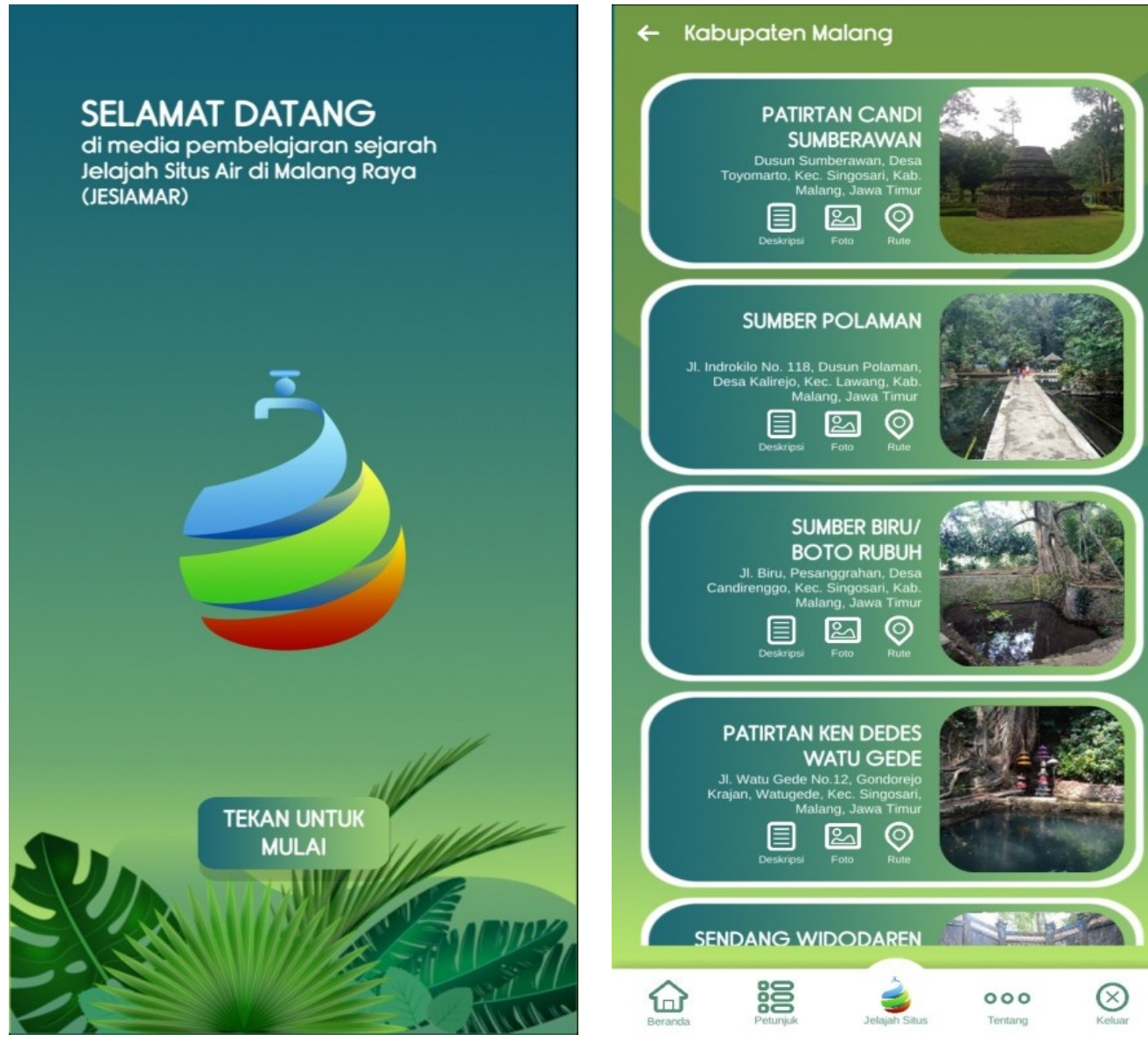

SENDANG WIDODAREN A Nefliget

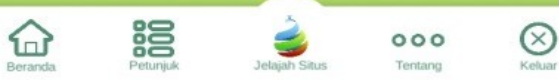

Gambar 1 Tampilan Aplikasi JESIAMAR (Dok. Pribadi, 2020)

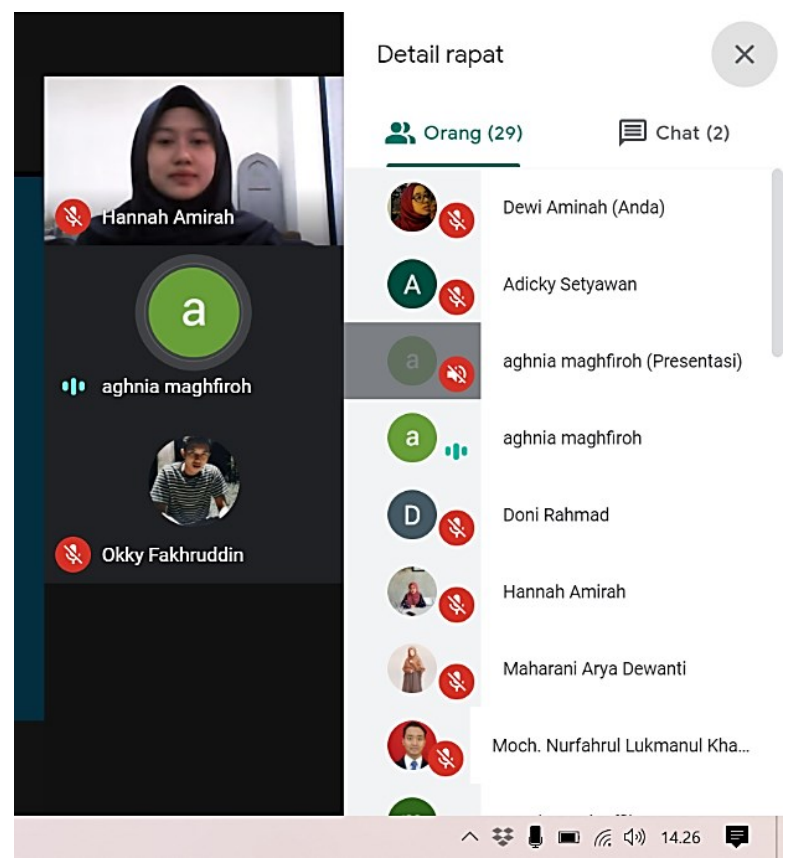

Gambar 2 Pelaksanaan Kegiatan Implementasi Secara Online (Dok Pribadi, 2020) 


\section{Pasca Kegiatan (Evaluasi)}

Setelah kegiatan inti berakhir, 20 siswa sebagai partisipan difasilitasi untuk mengisi kuesioner melalui aplikasi Google Form. Data kuesioner ini kemudian dianalisa dan menjadi tolak ukur efektifitas penggunaan aplikasi JESIAMAR pada pembelajaran sejarah. Penentuan efektif atau tidaknya suatu produk dapat ditentukan dengan kriteria efektifitas produk yang dapat dilihat pada tabel berikut.

Tabel 1 Kriteria Efektifitas Produk

\begin{tabular}{cc} 
Presentase (\%) & Kategori Efektifitas \\
\hline $80-100$ & Sangat efektif \\
$60-79$ & Efektif \\
$50-59$ & Agak efektif \\
$<50$ & Tidak efektif
\end{tabular}

Sumber: Sugiyono, (2008)

Belajar dapat diartikan sebagai rangkaian kegiatan atau aktifitas yang dilakukan secara sadar oleh seseorang dan mengakibatkan perubahan bagi dirinya berupa penambahan pengetahuan atau kemahiran berdasarkan alat indra atau pengalamannya (Pramono, 2012). Pada penggalian informasi selanjutnya yaitu mengenai peningkatan kesadaran akan pentingnya memahami sejarah lokal setelah kegiatan belajar menggunakan aplikasi JESIAMAR, $60 \%$ siswa memilih setuju dan 40\% lainnya memilih sangat setuju. Berikut ini adalah uraian mengenai hasil evaluasi yang telah dilakukan siswa berkaitan dengan sejarah lokal pada aplikasi JESIAMAR.

12. Aplikasi JESIAMAR meningkatkan kesadaran akan pentingnya mempelajari sejarah lokal. 20 tanggapan

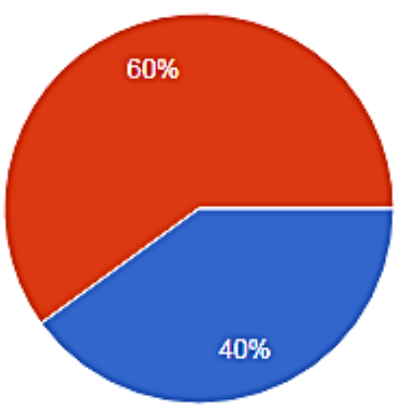

Sangat setuju

Setuju

Tidak setuju

Sangat tidak setuju

Gambar 3 Penilaian Mengenai Peningkatan Kesadaran Sejarah Lokal

Rangkaian materi yang diulas dalam aplikasi JESIAMAR diharapkan mampu memunculkan kecintaan siswa terhadap sejarah lokal. Ikatan jiwa yang kuat terhadap kedaerahan merupakan salah satu pondasi awal untuk memperkuat pengetahuan atau rasa cinta terhadap objek sejarah (Al Akhyar, 2020; W. D. Sulistyo et al., 2020). Berdasarkan pernyataan ini, 60\% siswa menilai setuju, sedangkan $40 \%$ lainnya memilih sangat setuju. 
13. Aplikasi JESIAMAR memunculkan kecintaan terhadap sejarah lokal.

20 tanggapan
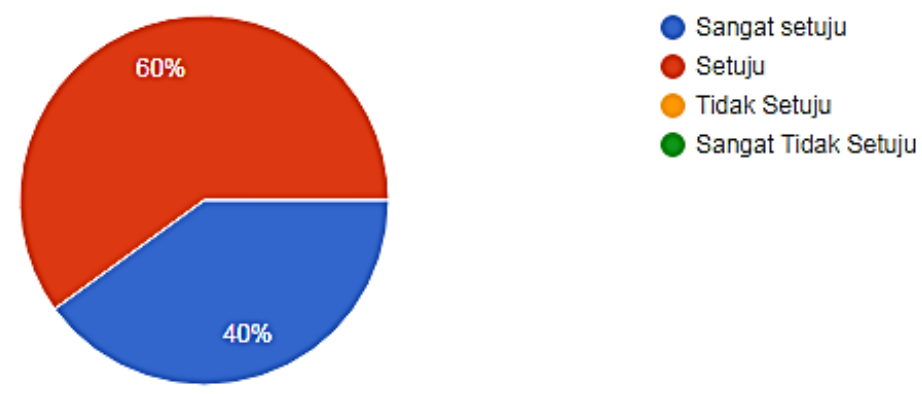

Gambar 4 Penilaian Tentang Kecintaan Terhadap Sejarah Lokal

Salah satu harapan dari pengajaran sejarah lokal adalah untuk memunculkan kebanggaan dan nasionalisme. Kebanggaan terhadap kejayaan masalalu bukan untuk melenakan, tetapi memunculkan pemaknaan baru terhadap jati diri bangsa (Kartodirdjo \& Pusposaputro, 1992). Selanjutnya yaitu berkenaan dengan ketercapaian aplikasi JESIAMAR dalam memunculkan rasa kebanggaan bagi siswa terhadap eksistensi sumber sejarah di lingkungan sekitar, 55\% siswa memilih setuju dan 45\%lainnya memilih sangat setuju dengan pernyataan tersebut.

\section{Pembelajaran sejarah lokal dengan aplikasi JESIAMAR memunculkan kebanggaan karena daerah tempat tinggal peserta didik menjadi bagian dari sejarah.}

20 tanggapan
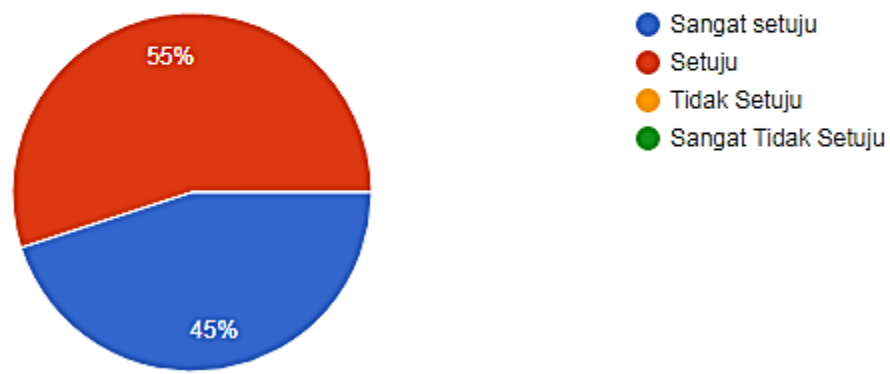

Gambar 5 Penilaian tentang Kebanggaan Terhadap Sejarah Lokal

Salah satu luaran terpenting dalam pembelajaran sejarah adalah agar siswa mau memiliki kepedulian terhadap sejarah dan berkontribusi dalam pelestarian peninggalan sejarah, terutama peninggalan sejarah di sekitar mereka. Untuk menggali informasi tersebut, pernyataan terakhir yang diajukan oleh tim pengabdi adalah pengetahuan yang didapatkan melalui pembelajaran menggunakan aplikasi JESIAMAR meningkatkan kepedulian terhadap pelestarian peninggalan sejarah lokal. Hasil evaluasi responden menunjukkan bahwa 55\% siswa menilai sangat setuju dengan pernyataan ini. sedangkan 45 lainnya memilih sangat setuju. Hal ini dapat ditampilkan pada gambar berikut. 
15. Pengetahuan yang didapatkan melalui pembelajaran menggunakan aplikasi JESIAMAR meningkatkan kepedulian terhadap pelestarian peninggalan sejarah lokal.

20 tanggapan

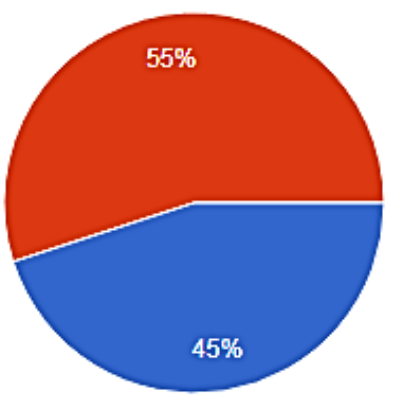

Sangat setuju

Setuju

Tidak setuju

Sangat tidak setuju

\section{Gambar 6 Penilaian Peningkatan Kepedulian dan Upaya Pelestarian Sejarah Lokal}

Untuk mengetahui presentase dari kuesioner ini, hasil evaluasi siswa diolah dan disajikan dalam bentuk presentase. Hasil evaluasi siswa ini dapat disajikan dalam tabel berikut :

Tabel 2 Hasil Evaluasi

\begin{tabular}{|c|c|c|c|c|c|}
\hline \multirow{2}{*}{ NO } & \multirow{2}{*}{ NAMA } & \multicolumn{4}{|c|}{ KESADARAN SEJARAH LOKAL } \\
\hline & & 8 & 9 & 10 & 11 \\
\hline 1 & Novan Febriansyah Azikin & 4 & 3 & 3 & 3 \\
\hline 2 & Novi Hartanti & 4 & 4 & 4 & 4 \\
\hline 3 & Reno Ardiansyah & 3 & 3 & 3 & 3 \\
\hline 4 & Putra Dwi Anugrah & 4 & 4 & 3 & 4 \\
\hline 5 & Vina Rahmawati & 4 & 4 & 4 & 4 \\
\hline 6 & Mochamad Raffli & 3 & 3 & 3 & 3 \\
\hline 7 & Syifa'ul Charisma & 3 & 3 & 3 & 3 \\
\hline 8 & Mochammad Wahyu Saputra & 3 & 3 & 4 & 3 \\
\hline 9 & Roqi Fakhruddin & 3 & 3 & 4 & 3 \\
\hline 10 & Siti Nafisatun Ni'matillah & 3 & 3 & 3 & 4 \\
\hline 11 & Siti Maisaroh & 3 & 3 & 3 & 3 \\
\hline 12 & Nita Devy Fauziah & 3 & 3 & 3 & 3 \\
\hline 13 & Paula Al Hidayah & 3 & 3 & 3 & 3 \\
\hline 14 & Rahma Widia Sutanti & 3 & 4 & 4 & 4 \\
\hline 15 & Natasya Putri Fatimah & 3 & 3 & 3 & 3 \\
\hline 16 & Olive Kyla Melandri & 4 & 4 & 4 & 4 \\
\hline 17 & Muhammad Asmaul Alif Ihzafry & 3 & 3 & 3 & 3 \\
\hline 18 & Salia Dewi Andriani & 4 & 4 & 4 & 4 \\
\hline 19 & Widira Nafajira & 4 & 4 & 4 & 4 \\
\hline 20 & Naswa Afiya Rosiana & 4 & 4 & 4 & 4 \\
\hline & TOTAL NILAI & \multicolumn{4}{|c|}{274} \\
\hline & TOTAL NILAI IDEAL & \multicolumn{4}{|c|}{320} \\
\hline & PRESENTASE & \multicolumn{4}{|c|}{$85,6 \%$} \\
\hline
\end{tabular}

Dalam bentuk presentase, hasil evaluasi yang telah dilakukan siswa menunjukkan penilaian mengenai kesadaran sejarah lokal sebesar $85,6 \%$. Berdasarkan hasil evaluasi ini maka dapat dinyatakan bahwa sejarah lokal yang terkemas dalam aplikasi JESIAMAR sangat efektif untuk diimplementasikan dalam pembelajaran. Lebih dari sekadar hafalan, mengenali eksistensi para 
pendahulu di sejarah lokal dengan aplikasi JESIAMAR akan memperkuat kedekatan emosional siswa terhadap sejarah, sehingga mereka mampu menikmati pengalaman belajar dan memaknai pembelajaran. Belajar sejarah dengan mengenal secara langsung situs-situs sejarah yang berada di sekitar kita akan menumbuhkan kesadaran yang kuat terhadap pemahaman sejarah (W.D Sulistyo, 2019a).

\section{KESIMPULAN}

Kegiatan implementasi masyarakat "Implementasi Aplikasi Model Pembelajaran 'Jelajah Situs Air Malang Raya' untuk Menumbuhkan Kesadaran Sejarah Lokal dan Upaya Pelestarian Situs Sejarah Bagi Siswa SMKN 2 Singosari” telah terselenggara dengan baik. Kegiatan yang diikuti oleh siswa kelas X MM 3 dan X EI 2 secara online melalui aplikasi Google Meet. Kegiatan terbagi menjadi (1) pra kegiatan yang meliputi perencanaan dan kesepakatan kerjasama dengan pihak mitra; (2) pelaksanaan kegiatan yang meliputi penyampaian materi situs air, sosialisasi aplikasi JESIAMAR dan diskusi; (3) pasca kegiatan yang meliputi evaluasi, penyusunan laporan serta luaran kegiatan implementasi. Hasil dari kegiatan implementasi masyarakat ini adalah tambahan pengetahuan bagi siswa mengenai pemanfaatan aplikasi digital JESIAMAR, sejarah lokal situs air di Malang Raya. Kuesioner evaluasi yang telah diisi siswa menunjukkan penilaian mengenai kesadaran sejarah lokal sebesar 85,6\%. Berdasarkan hasil evaluasi ini maka dapat dinyatakan bahwa aplikasi JESIAMAR sangat efektif untuk diimplementasikan dalam pembelajaran.

Kesimpulan yang mengacu pada tujuan. Proporsi maksimal 10\%. Hindari kesimpulan berupa poin-poin dalam bentuk angka maupun bullet. Dianjurkan berupa kalimat-kalimat sederhana yang menyimpulkan hasil penelitian.

\section{DAFTAR PUSTAKA}

Al Akhyar, A. A. I. (2020). Mengunjungi Simbol-Simbol Sejarah Lokal Tulungagung: Diandra Kreatif. Diandra Kreatif.

Ali, R. M. (2005). Pengantar ilmu sejarah Indonesia. LKIS PELANGI AKSARA.

Arifin, Z. (2009). Evaluasi pembelajaran (Vol. 8). Bandung: Remaja Rosdakarya.

Kartodirdjo, S., \& Pusposaputro, S. (1992). Pendekatan ilmu sosial dalam metodologi sejarah. Gramedia Pustaka Utama.

Kuntowijoyo. (2013). Pengantar Ilmu Sejarah. Tiara Wacana.

Latuheru, J. D. (1988). Media pembelajaran dalam proses belajar mengajar masa kini. Jakarta: Depdikbud.

Pramono, S. E. (2012). Perbaikan kesalahan konsep pembelajaran sejarah melalui metode pemecahan masalah dan diskusi. Paramita: Historical Studies Journal, 22(2).

Prastowo, A. (2014). Pengembangan Bahan Ajar Tematik Tinjauan Teoritis dan Praktik (2nd ed.). Kencana.

Sayono, J., Ayundasari, L., Sulistyo, W. D., \& Ridho'i, R. (2019). Situs Sejarah Malang Raya Masa Islam dan Kolonial. Jurusan Sejarah FIS UM.

Semiawan, C. R. (2010). Metode penelitian kualitatif. Grasindo.

Sugiyono. (2008). Metode penelitian pendidikan:(pendekatan kuantitatif, kualitatif dan $R \& D)$. Alfabeta.

Sugiyono, S. (2013). Metode Penelitian Kualitatif. Bandung: Alfabeta. 
Sulistyo, W. D., Khakim, M. N. L., Kurniawan, B., \& S, A. D. (2020). Learning experience from learning sources: Exploiting geographic and historical potential of guerrilla sites in Wonokarto Pacitan as a source of historical learning. IOP Conference Series: Earth and Environmental Science, $\quad 485, \quad 012109$. https://doi.org/10.1088/17551315/485/1/012109

Sulistyo, Wahyu Djoko, K, M. N. L., \& Kurniawan, B. (2020). The Development of "JEGER" Application Using Android Platform as History Learning Media and Model. International Journal of Emerging Technologies in Learning (IJET), 15(07), 110-122.

Sulistyo, W.D. (2019a). BAKTI DAN PENGENALAN SITUS CANDI KALICILIK PADA SISWA SD 1 CANDIREJO PONGGOK BLITAR. 8.

Sulistyo, W.D. (2019b). Learning Activities from Learning Resources: Pemanfaatan dan Pemaknaan Situs Sejarah Kawasan Alun-Alun Merdeka Kota Malang. Jurnal Pendidikan Sejarah Indonesia, 2(1), 49-63. 